\title{
ESTETIKA MASKULIN DAN EKSKLUSI PEREMPUAN DALAM FILM EKO-KRITIK SEORANG KAMBING (2016)
}

\author{
MASCULINE AESTHETICS AND EXCLUSION OF WOMEN \\ IN THE ECO-CRITICAL FILM SEORANG KAMBING (2016)
}

\author{
*Ratna Noviani \\ Program Studi Kajian Budaya dan Media \\ Sekolah Pascasarjana Universitas Gadjah Mada \\ Submitted: 09-11-2018; Revised: 28-08-2019; Accepted: 28-08-2019
}

\begin{abstract}
The eco-critical film, Seorang Kambing (Tunggung Banjaransari, 2016), is part of eco-cinema, which mainly talks about problems of water crisis throughout its narrative. Eco-cinema has not only audiovisual presentations regarding environmental issues, but also functionalizes aesthetic choices, which could encourage viewers to have mindful and critical awareness of ecological problems. This article is aimed to examine how the film narrative of Seorang Kambing reproduces gender problems around the issue of water crisis. This article uses Stella Bruzzi's (2013) concept of masculine aethetics in the cinema and the approach of eco-feminism, which critically reveals the connections between the oppressions of the nature and those toward women. By applying narrative analysis, which is presented by Helen Fulton (2005), this article reveals that masculine aethetics are functionalized predominantly in the film to narrate the problems of water crisis. Paradoxically, Seorang Kambing, as an intended eco-critical film, seems to simply overlook the significant roles of women around the issue of water crisis. In addition, the film reproduces the exclusion of women from the discourse of water crisis.
\end{abstract}

Keywords: Ecofeminism; Eco-cinema; Eco-criticism; Masculine aesthetic; Water crisis.

\begin{abstract}
ABSTRAK
Film eko-kritik berjudul Seorang Kambing (Tunggul Banjaransari, 2016) merupakan bagian dari ecocinema yang mengangkat persoalan krisis atau kelangkaan air dalam naratif filmnya. Eco-cinema bukan hanya film yang bercerita tentang isu lingkungan tetapi juga menggunakan berbagai pilihan estetik yang mampu mendorong penonton untuk memiliki kesadaran kritis tentang lingkungan. Artikel ini mengkaji bagaimana naratif film Seorang Kambing mereproduksi problem gender dalam wacana krisis air. Film dikaji dengan menggunakan konsep estetika maskulin dalam film dari Stella Bruzzi (2013) dan pendekatan ekofeminisme yang mengulas secara kritis adanya keterkaitan antara penindasan terhadap alam dan penindasan yang dialami perempuan. Dengan menggunakan metode analisis naratif yang digunakan oleh Helen Fulton (2005), kajian dalam artikel ini menunjukkan adanya dominasi estetika maskulin yang difungsikan oleh film tersebut untuk menarasikan problem krisis air. Sebagai sebuah
\end{abstract}

${ }^{*}$ Corresponding author: Email: ratna.noviani@ugm.ac.id

Copyright@ 2019 THE AUTHOR(S).This article is distributed under a Creative Commons Attribution-Share Alike 4.0 International license. Jurnal Kawistara is published by the Graduate School of Universitas Gadjah Mada. 
film eko-kritik, film Seorang Kambing cenderung tidak sensitif pada peran perempuan dan justru mereproduksi eksklusi perempuan dari wacana kelangkaan air.

Kata kunci: Eco-cinema; Ekofeminisme; Ekokritik; Estetika maskulin; Krisis air.

\section{PENGANTAR}

Problem kelangkaan air telah menjadi isu yang dominan sejak tahun 1980-an di berbagai negara. Di Asia Tenggara, air juga menjadi salah satu isu yang paling penting, sejalan dengan makin luasnya ekspansi dan pembangunan ekonomi di wilayah tersebut. Menurut Sim dan Balamurugan (1991: 195), problem air di kawasan Asia Tenggara merupakan salah satu akibat dari abainya hasrat perluasan ekonomi pada konservasi lingkungan. Hal senada juga diungkapkan oleh Onn dan Yia (2013: 1) bahwa pertumbuhan penduduk dan aktivitas pembangunanlah yang menjadi penyebab utama dari merosotnya ketersediaan air bersih di wilayah Asia Tenggara, tak terkecuali di Indonesia. Bersama Myanmar, Indonesia adalah negara di Asia Tenggara yang memiliki akses buruk pada sanitasi dan sumber air yang berkelanjutan pada rentang 1990 hingga 2006. Data yang disampaikan oleh Lembaga Ilmu Pengetahuan Indonesia (LIPI) pada tahun 2012 menunjukkan bahwa Indonesia masih berada di tempat terburuk dalam pelayanan ketersediaan air bersih dan layak konsumsi se-Asia Tenggara (Media Indonesia, 2016). Hal ini diperkuat oleh kajian yang dilakukan oleh Bappenas dalam Rencana Pembangunan Jangka Menengah Nasional (RPJMN) Bidang Kehutanan dan Konservasi Sumber Daya Air pada tahun 2018, yang menyebutkan bahwa pada tahun 2016 Pulau Jawa dan Sumbawa bahkan sudah defisit air bersih. Kondisi ini diperkirakan akan terus berlanjut hingga 2020. Pada 2024, wilayah Pulau Jawa bahkan diprediksi akan berada pada zona merah atau kritis ketersediaan air bersih (kompas.com, 2019). Kemajuan ekonomi yang semakin pesat telah berdampak pada kebutuhan air yangjuga semakin meningkat. Sementara, pada sisi yang lain, ketercukupan pasokan atau ketersediaan air tidakmendukung. Belum lagiadanya praktik penggunaan air bawah tanah secara ilegal yang dilakukan oleh perusahaan-perusahaan besar. Di beberapa kota besar di Indonesia, seperti di Jakarta, banyak gedung tinggi dan hotel yang menyedot dan memanfaatkan air bawah tanah tanpa dilengkapi dengan SIPA atau surat izin pengambilan air bawah tanah. Hal ini menjadi salah satu faktor yang menyebabkan semakin minimnya ketersediaan air bersih bagi warga (Republika.co.id, 2018). Tak heran jika krisis air bersih merupakan ancaman serius yang ada di depan mata.

Untuk menangani persoalan lingkungan seperti problem krisis dan kelangkaan air, diperlukan kerja sama dan kesadaran dari berbagai pihak, baik dari negara, korporasi maupun elemen masyarakat. Kampanye untuk menangani dan mengatasi persoalan krisis air perlu digaungkan seluas mungkin. Film menjadi salah satu media yang bisa digunakan untuk mewacanakan persoalan lingkungan, termasuk persoalan kelangkaan air tersebut. Peran film, meskipun sering dianggap kecil, tetapi sangat penting untuk menstimulasi penonton agar memiliki kepedulian maupun kesadaran tentang isu-isu lingkungan (lihat Rust dan Monani, 2013; MacDonald, 2013). Berangkat dari pemahaman tersebut, kajian dalam artikel ini akan fokus pada teks film yang menarasikan problem kelangkaan air bersih yang terjadi di Indonesia, yaitu film Seorang Kambing (2016) yang disutradarai oleh Tunggul Banjaransari. Film ini menarik untuk dikaji tidak hanya karena film ini mengangkat problem yang faktual dan aktual di Indonesia terkait ketersediaan air bersih, tetapi juga karena film ini juga menampilkan kelindan antara isu gender dan isu lingkungan di dalam naratifnya. Dengan menggunakan konsep masculine aesthetic dalam film dari Stella Bruzzi (2013) dan pendekatan ekofeminisme, yang pada dasarnya mengkritisi keterkaitan antara penindasan terhadap alam dan penindasan terhadap perempuan, artikel ini mengkaji tentang bagaimana estetika film yang digunakan dalam Seorang Kambing (2016) bekerja secara ideologis untuk mengeksklusikan peran perempuan dalam persoalan krisis air. Konsep masculine aesthetic dari Stella Bruzzi 
bisa membantu menguak cara kerja ideologis dari naratif film dalam menampilkan dan menyampaikan jalinan cerita. Konsep ini juga menunjukkan detil-detil dari pilihan estetik yang bisa difungsikan untuk membangun pemahaman dan mereproduksi maskulinitas dominan dalam masyarakat patriarkhal.

Korpus dari kajian dalam artikel ini adalah film pendek berjudul Seorang Kambing, yang diproduksi pada tahun 2016 dan disutradarai oleh Tunggul Banjaransari. Film ini adalah satu dari lima film yang terangkum dalam film omnibus Prakarti: Cerita Tentang Perubahan Iklim dan Kita, yang diproduksi oleh Prakarti bekerjasama dengan Kedutaan Besar Jerman di Indonesia. Seperti dijelaskan di laman resmi Prakarti, film omnibus tersebut bertujuan untuk mengajak masyarakat melihat kembali relasi manusia dengan lingkungan di mana mereka hidup (Prakarti, 2016). Film Seorang Kambing dipilih sebagai korpus kajian dalam artikel ini karena film tersebut secara spesifik menarasikan tentang problem kelangkaan air bersih yang memang sangat kontekstual dengan problem yang terjadi di Indonesia dan bagaimana isu gender terlibat di dalamnya. Film dikaji dengan menggunakan analisis naratif dengan mengacu pada kajian yang dilakukan oleh Helen Fulton (2005). Dalam artikelnya yang berjudul "Film Narrative and Visual Cohesion", Fulton mencontohkan penggunaan analisis naratif pada film The Lord of the Rings: The Fellowship of The Ring (2001) dan film The English Patient (1996). Fulton memfokuskan terutama pada elemen naratif berupa suara, karakter, fokalisasi (sudut pandang atau perspektif yang digunakan untuk menarasikan cerita) dan kohesi (cara di mana film diorganisir, sehingga beragam elemen yang terlibat di dalamnya terkait dan terikat membentuk sebuah peristiwa yang komplet) diaktifkan dalam film untuk membangun makna-makna tertentu. Cara yang dilakukan Fulton diterapkan untuk mengkaji film Seorang Kambing di dalam artikel ini. Dengan memberikan perhatian pada elemen-elemen naratif tersebut, bisa diidentifikasi cara pandang yang mendasari bangunan cerita dari film yang memuat isu lingkungan dan keterkaitannya dengan isu gender. Bagaimana alam diposisikan dalam relasinya dengan manusia dan bagaimana isu gender berkelindan dengan isu lingkungan bisa dilihat melalui karakterisasi, fokalisasi dan kohesi dalam film.

\section{PEMBAHASAN Film Seorang Kambing sebagai Eco- cinema}

Isu tentang kelangkaan air menjadi perhatian utama dari film Seorang Kambing yang disutradarai oleh Tunggul Banjaransari (2016). Film berdurasi 20 menit 50 detik ini bercerita tentang kelangkaan air di sebuah desa yang tidak begitu jelas nama lokasinya, di mana dan kapan terjadinya. Keringnya sumber air tanah dan munculnya korporasi besar membuat air menjadi langka dan mahal. Seorang pemuda desa dibantu pamannya memiliki ide untuk membuat ramuan air minum dari bensin. Dalam film itu, air menjadi jauh lebih mahal daripada bensin. Air minum dari bensin itu diceritakan memberikan kekuatan tertentu yang membuat kelompok bela diri di desa itu maupun satu kompi tentara memiliki kekuatan lebih dan menjadi sakti. Kelangkaan air tidak hanya mendera warga yang tinggal di desa itu, tetapi juga membuat binatang-binatang yang hidup berubah menjadi batu. Oleh karena itu, warga merasa perlu untuk melindungi kambing-kambing piaraan mereka agar tidak hilang atau berubah menjadi batu.

Film itu juga bercerita tentang seorang laki-laki yang menggunakan motor trail yang biasa dipanggil 'Mas Trail'. 'Mas Trail' selalu membawa dan memberikan air dalam kemasan botol kepada warga desa. Laki-laki ini kemana-mana mengenakan tas berbentuk kepala harimau. Ia bersembunyi di sebuah gua dan diam-diam berteman dengan pimpinan kelompok bela diri di desa tersebut. Kelompok silat ini digambarkan datang kepada warga desa dan mendata kambing-kambing siapa saja yang hilang. Kambing yang hilang akan ditukar dengan kambing pinjaman oleh kelompok silat tersebut. Warga desa sendiri meyakini bahwa penyebab hilangnya kambing-kambing adalah seekor harimau yang bersembunyi di sebuah 
gua. Di bagian akhir film diceritakan bahwa warga dibantu oleh tentara dan kelompok silat melakukan penggerebekan terhadap harimau yang disinyalir mencuri kambingkambing warga. Sementara, pemuda desa yang memproduksi air minum bensin juga datang ke gua itu dan menaklukkan 'Mas Trail' yang bersembunyi di sana dengan cara memukul kepalanya hingga pingsan. Setelah itu, si pemuda menggambari belang-belang mirip harimau pada tubuh 'Mas Trail' dan mengenakan tas kepala harimau di kepalanya. Dari dalam gua, pemuda itu berteriak bahwa harimaunya sudah pingsan.

Gagasan utama dari film ini tampaknya berangkat dari keprihatinan pada krisis dan kelangkaan air yang terjadi akibat proses industrialisasi. Film tersebut memuat pesan eksplisit tentang kesadaran lingkungan, khususnya tentang krisis kelangkaan air bersih. Secara spesifik, film Seorang Kambing menyampaikan kritik ekologi terkait kelangkaan sumber air sebagai dampak dari pengadaan air yang tidak berkelanjutan serta program komersialisasi air yang terjadi dalam konteks Indonesia. Dilihat dari narasinya itu, film Seorang Kambing bisa dimasukkan dalam kategori eco-cinema. Merujuk pada pendapat Paula Willoquet-Maricondi, 2010: 9-10) dalam bukunya Framing the World: Explorations in Ecocriticism and Film, film yang secara terbuka menunjukkan perhatian dan partisipasi pada isu-isu keadilan lingkungan disebut sebagai eco-cinema. Ia mengatakan bahwa eco-cinema meliputi beragam genre dan moda produksi seperti film fiksi panjang dan pendek, film dokumenter maupun film eksperimental. Akan tetapi secara spesifik Willoquet-Maricondi mengatakan bahwa film-film yang berorientasi profit seperti film-film produksi Hollywood tidak bisa dikategorikan sebagai eco-cinema karena film-film seperti itu lebih meneguhkan hasrat konsumeristik yang cenderung merusak lingkungan daripada menstimulasi kesadaran kritis akan problem lingkungan. Film yang memuat kritik ekologi, menurut WilloquetMaricondi, merupakan bentuk aktivisme karena film seperti itu bisa membangun kesadaran dan tanggung jawab tentang persoalan lingkungan serta menstimulasi tindakan politik dan konservasi lingkungan. Senada dengan Willoquet-Maricondi, Alex dan Deborah (2016: 2) secara spesifik mendefinisikan eco-cinema sebagai "activist documentaries" atau "documentaries with clear environment concerns". Sementara itu, David Ingram (2013: 44) lebih memilih menyebutnya sebagai eco-film, yaitu "a film that has a conceptual content, which more or less explicitly promotes ecological ideas, or more generally an ecological sensibility".

Munculnya film-film yang secara khusus memberikan perhatian pada persoalan lingkungan juga memicu perkembangan kajian tentang eco-criticism atas film-film tersebut. Meskipun demikian, harus diakui bahwa penggunaan perspektif eko-kritik dalam berbagai kajian akademik, termasuk dalam ranah kajian film, masih relatif sedikit (Rust dan Monani, 2013: 2). Mengkaji teks film dengan perspektif eco-criticism pada dasarnya tidak cukup jika hanya memfokuskan pada bagaimana film-film tersebut merepresentasikan alam atau menggambarkan hubungan manusia dengan alam saja. Terkait dengan hal itu, Adrian Ivakhiv (2012: 145) mengatakan, "Thinking about films ecocritically involves not only examining representations of nature, or of human-nature relations, within films; it must also involve examine the film medium itself...". Ivakhiv menggarisbawahi pentingnya mengkaji medium film itu sendiri daripada hanya sekedar menganalisis bagaimana gambaran tentang alam maupun tentang relasi manusia dengan alam di dalam film. Medialitas film dan kerja aparatus sinematik dalam menarasikan persoalan lingkungan perlu mendapatkan perhatian dalam kajian eco-criticism atas sebuah film. Hal yang sama juga diungkapkan oleh David Ingram (2013) dalam kajiannya tentang peran estetika film dalam membangun pemahaman yang lebih baik tentang isu lingkungan. Ingram (2013: 43) menyebutkan bahwa pilihan estetika film ikut berperan dalam membangun pemahaman kritis tentang isu lingkungan yang ingin disampaikan-Ingram mencontohkan kajian Paula Willoquet-Maricondi (2010) dan Scott MacDonald (2013) yang menganalisis pilihan- 
pilihan estetika semacam penggunaan slow pacing atau long takes untuk mengarahkan upaya kontemplasi atas isu yang terkait dengan kerusakan lingkungan.

Estetika film, menurut Michael Rabiger (2008: 159), terkait dengan bagaimana konten film akan ditampilkan. Pilihan estetika akan menentukan bagaimana sebuah film akan ditampilkan dan bagaimana jalinan cerita akan disampaikan. Dalam konteks gender, misalnya, estetika film juga menjadi faktor yang signifikan dalam membangun pemahaman tentang femininitas dan maskulinitas. Dalam bukunya Men's Cinema: Masculinity and Mise en Scene in Hollywood, Stella Bruzzi (2013), menegaskan peran estetika dalam membangun pemahaman tentang maskulinitas. Kajian tentang bagaimana naratif film bekerja secara ideologis untuk membangun pemahaman tentang maskulinitas sebetulnya pernah dilakukan oleh Steve Neale (1983). Dalam esainya yang berjudul Masculinity as Spectacle: Reflections on Men and Mainstream Cinema, Neale menyoroti kecenderungan film-film arus utama produksi Hollywood dalam membangun citra maskulinitas. Berangkat dari kajian yang dilakukan oleh Laura Mulvey (1975) tentang film-film klasik Hollywood yang cenderung memposisikan perempuan dalam perspektif dan tatapan laki-laki, Neale lebih memberikan perhatian pada bagaimana film membangun citra laki-laki ideal. Naratif film, menurut Neale, cenderung mendudukkan tubuh maskulin sebagai yang kuat dan punya kuasa. Figur laki-laki, dalam hal ini, dicegah untuk tampak lemah, erotis, atau terlihat feminin. Dalam pandangan Neale, citra tentang laki-laki ideal itu turut mendorong penonton [laki-laki] untuk mengidentifikasi dan mendaku pada figur laki-laki ideal yang digambarkan oleh film.

Berbeda dengan Neale yang mengkaitkan antara citra maskulin dalam naratif film dengan praktik identifikasi yang terjadi pada diri penonton, Stella Bruzzi lebih menekankan pada peran ideologis dari pilihan-pilihan estetika yang digunakan di dalam film. Bruzzi (2013: 94) menyebutnya sebagai "masculine aesthetic". Ia mengatakan bahwa estetika maskulin bukan sekedar pengaturan elemen-elemen stylistic untuk mengekspresikan maskulinitas. Lebih dari itu, estetika maskulin adalah "...a set of underlying principle...that collectively assists an understanding or definition of 'masculinity' in cinema". Jadi, estetika maskulin dalam film merupakan basis yang mendasari cara-cara film tersebut memahami dan mendefinisikan maskulinitas. Dengan kata lain, konstruksi maskulinitas dibangun melalui beragam pilihan estetik yang pada dasarnya bias gender dan mereproduksi pandangan dominan dalam masyarakat patriarkhal. Dalam pendekatan ekofeminisme (lihat Mies dan Shiva, 2014; Ruether, 2001) prinsip-prinsip yang cenderung bias maskulin yang menjadi basis pemahaman tentang isu lingkungan perlu mendapatkan perhatian dan perlu dikritisi. Dalam perspektif eko-kritik, film tentang lingkungan perlu juga menyadari problem gender yang melingkupi persoalan lingkungan. Pilihan estetika film yang cenderung bias gender bisa membawa implikasi pada distorsi wacana lingkungan yang dibangun di dalam film tersebut.

\section{Krisis Air dalam Pendekatan Ekofeminisme}

Air yang awalnya merupakan hak bagi setiap makhluk hidup telah berubah menjadi marketable commodity dan menjadi bisnis besar yang dikelola oleh korporasi-korporasi global. Seperti yang diungkapkan oleh Vandana Shiva (2001: 20), "[G]lobalization and privatization of water resources completely erode people's rights and replace collective ownership with corporate control are under way". Dalam hal ini, manajemen air yang tadinya dikelola bersama oleh masyarakat diambil alih oleh korporat. Penyediaan air berubah menjadi agenda ekonomi neo-liberal melalui program-program privatisasi maupun desentralisasi.

Fenomena krisis air sendiri pada dasarnya cenderung maskulin akibat dari dikotomi nature/culture dalam memandang relasi alam dengan manusia. Kaum ekofeminis mengkritisi cara pandang dalam masyarakat patriarkhal yang memosisikan perempuan sebagai "being closer to the nature" (Ruether, 2001: 230). Lakilaki sebagai kategori culture dipahami sebagai 
pihak yang punya kuasa dan cenderung mendominasi nature. Alam dimetaforakan sebagai yang feminin, oleh karenanya, perempuan dan alam memiliki pengalaman paralel sebagai pihak yang didominasi. Rusaknya alam adalah juga rusaknya kehidupan perempuan, karena perempuan lah korban terburuk dari kerusakan alam akibat dari beragam peran sosial yang dilekatkan padanya, kemiskinan dan juga minimnya akses pada berbagai sumber daya (Eaton dan Lorentzen, 2003: 2).

Problem kelangkaan dan komersialisasi air, perempuan dan anak-anak adalah korban yang paling banyak menderita (Shiva 1988; Wallace dan Coles, 2005). Hak perempuan atas air sangat sedikit mendapatkan perhatian. Perempuan juga cenderung mengalami marginalisasi atau bahkan eksklusi dalam beragam kebijakan yang terkait dengan manajemen dan pengadaan air. Padahal dalam masyarakat patriarkhal, perempuan menjadi penyedia utama air untuk kebutuhan keluarga. Perempuan juga memiliki pengalaman dan keterampilan tentang siklus air dan konservasi air secara natural (Shiva, 1995: 201). Ketika muncul masalah kelangkaan air, perempuan memiliki pengalaman empiris dalam menghadapi dan mengatasi persoalan krisis air ini. Tidak heran jika perempuan pada dasarnya adalah "the guardians of environment" (Wallace dan Coles, 2005: 3). World Water Forum (2003) bahkan menggarisbawahi beragam bukti yang jelas menunjukkan betapa pentingnya peran perempuan dalam program penyediaan air bersih. Akan tetapi, berbagai kebijakan dan regulasi tentang manajemen air masih cenderung meminggirkan atau bahkan mengeksklusikan peran perempuan. Perhatian pada hak-hak perempuan atas air juga masih sangat minim. Intervensi negara dan privatisasi air membuat peran perempuan digantikan dengan teknologi dan programprogram manajemen yang dibangun dengan paradigma yang sangat maskulin. Sebagai bagian dari korban krisis kelangkaan air, perempuan dikorbankan secara berulang oleh sistem maskulin yang mengabaikan peran, suara dan pengalaman perempuan dalam mengatasi krisis kelangkaan air.

\section{Estetika Maskulin dan Reproduksi Eksklusi Perempuan dalam Narasi Film Seorang Kambing}

Krisis air yang diakibatkan oleh privatisasi air merupakan isu yang dengan jelas dinarasikan dalam film Seorang Kambing. Manajemen air yang tadinya dikelola oleh masyarakat berubah menjadi bagian dari agenda ekonomi neo-liberal. Hal ini terkait dengan fakta yang disampaikan oleh Vandana Shiva (2001: 19) bahwa kepentingan ekonomi neo-liberal membuat air tidak lagi menjadi properti publik, tetapi menjadi komoditas yang harus diperoleh dan diperdagangkan dengan bebas. Akses pada sumber air menjadi tidak merata, karena kepentingan publik menjadi subordinat dari kepentingan politik negara dan kepentingan pasar. Privatisasi, dalam pandangan Shiva, tidak hanya merusak sumber daya air yang ada tetapi juga mengeksklusikan dan karenanya menutup akses masyarakat miskin pada air. Problem privatisasi air ini dinarasikan di dalam film Seorang Kambing melalui simbolisasi air minum yang dikemas dalam botol berlabel yang dibawa dan dibagikan oleh 'Mas Trail'. Buasnya korporat-korporat yang mengomersialkan air juga dimetaforakan dengan harimau yang buas, yang menjadi penyebab hilangnya kambing-kambing warga desa. Harimau ini disimbolisasi dengan tas yang berbentuk kepala harimau, yang selalu ditenteng oleh tokoh 'Mas Trail'. Kemampuan 'Mas Trail' untuk berbicara dalam bahasa Inggris pada pimpinan kelompok bela diri [pada menit 09:41] dapat jadi merepresentasikan korporasi trans-nasional yang ikut menjadi pemain utama dalam program privatisasi air. Air dalam kemasan botol merupakan simbolisasi dari air telah berubah menjadi economic good yang diperjualbelikan.

Fakta bahwa air telah berubah menjadi komoditas ekonomi juga digambarkan lewat pemuda desa yang membuat air minum dari bensin dan dijual pada pelanggan di desa itu. Hanya mereka yang memiliki uang yang 
sanggup membeli air minum dari bensin ini. Prinsip ekonomi menjadi basis dari pengadaan air. Komersialisasi air yang dilakukan oleh industri besar, pada akhirnya ditiru dan direproduksi oleh warga masyarakat. Prinsip survival for the fittest, dalam hal ini, menjadi basis dari praktik ekonomi dan bisnis yang berorientasi pada kompetisi dan individualisme. Praktik inilah yang semakin meminggirkan dan menutup akses masyarakat miskin pada air karena mereka tidak memiliki sumber daya yang memadai untuk mengikuti proses dan mekanisme pasar. Praktik semacam ini juga memunculkan beragam praktik kolusi dan konspirasi demi keuntungan pribadi dan kelompok, seperti yang digambarkan melalui konspirasi antara tokoh laki-laki bermotor trail atau 'Mas Trail' dengan pimpinan kelompok bela diri di desa tersebut. Keduanya berkolaborasi [meski dalam film ini tidak terlalu jelas seperti apa bentuknya] dengan kepentingan yang berseberangan dengan warga masyarakat desa.

Fakta bahwa perempuan sering menjadi korban dan mengalami marginalisasi akibat privatisasi air oleh korporasi, seperti yang diungkapkan oleh Vandana Shiva (1988) maupun Wallace dan Coles (2005), juga digambarkan di dalam film Seorang Kambing. Sayangnya, film tersebut tidak menjadikan ruang representasi film sebagai ruang di mana suara dan perspektif perempuan dalam hal manajemen dan pengadaan air disuarakan. Yang terjadi justru sebaliknya, film Seorang Kambing mengaktifkan medialitas film, khususnya pilihan-pilihan estetik, untuk mereproduksi marginalisasi atau bahkan eksklusi terhadap perempuan. Sebagai sebuah film eko-kritik yang idealnya mengembangkan sensitivitas pada isu lingkungan, film ini justru tidak sensitif pada problem gender yang melingkupi persoalan krisis dan pengadaan air. Film ini cenderung mengabaikan perspektif ekofeminis dan melihat krisis air dengan sudut pandang yang cenderung bias laki-laki. Dominasi estetika maskulin dalam film tersebut ikut berperan dalam proses peminggiran dan eksklusi perempuan.
Merujuk pada tulisan Stella Bruzzi (2013) dalam bukunya Men's Cinema: Masculinity and Mise en Scene in Hollywood, ada beberapa cara untuk memformulasikan "bahasa lakilaki" dalam sebuah film. Bruzzi memang fokus mengkaji film-film fiksi Hollywood dan menelisik dengan detail bagaimana film-film semacam Once Upon A Time in the West (Sergio Leone, 1969) atau Dirty Harry (Don Siegel, 1971) membangun "the language of men's cinema" (2013: 69). Film dengan masculine aesthetics cenderung melakukan penguatan-penguatan pada konstruk maskulinitas dominan melalui style, karakterisasi maupun naratif. Seperti dijelaskan sebelumnya, Stella Bruzzi (2013: 94) mendefinisikan masculine aesthetic sebagai "a language, a set of underlying principles, a mode of communication and a series of signs, tropes and aesthetic features that collectively assists an understanding of 'masculinity' in cinema". Kesemua aspek yang disebutkan Bruzzi itu berfungsi dan bekerja secara sinergis untuk membangun pemahaman maupun definisi tentang maskulinitas.

Film Seorang Kambing juga memilih untuk memfungsikan estetika maskulin dalam membicarakan tentang krisis kelangkaan air. Satu hal yang paling tampak dari formulasi bahasa maskulin dalam film tersebut adalah absennya karakter perempuan secara visual dari mise-en-scène. Sentralisasi laki-laki dalam naratif film terlihat sangat menonjol. Tak ada satu pun visualisasi perempuan yang ikut bercerita atau ikut andil menanggung atau mengatasi krisis kelangkaan air. Padahal seperti sudah diungkapkan sebelumnya, banyak fakta yang menunjukkan bahwa korban paling menderita dari krisis kelangkaan air adalah perempuan dan anak-anak (Shiva, 1988; 173). Perempuan memiliki banyak pengalaman empiris dalam menghadapi problem kelangkaan air dan cukup menarik dari film ini adalah ada semacam indikasi adanya ruang emansipasi bagi perempuan dengan hadirnya suara perempuan yang membicarakan tentang krisis air di tempat tinggal mereka. Di bagian awal film ini [menit 00.45-01.37] terdengar voice over perempuan, tanpa nama, hanya menyebut "aku". Kehadiran voice over 
perempuan ini seperti menjanjikan bahwa narasi akan berjalan dan diarahkan dengan sudut pandang atau perspektif "aku" yang notabene seorang perempuan. Akan tetapi, rupanya kehadiran suara perempuan hanya berhenti di awal film saja. Itupun tidak jelas identitasnya, anonim, tanpa nama, dan tanpa wajah. Dari segi naratif, jelas ada keengganan untuk mengakui identitas si perempuan. Ia lebih banyak merujuk dirinya sebagai istri, sebuah peran domestik yang sebetulnya justru sangat kaya dengan pengalaman yang terkait dengan krisis dan pengadaan air. Sayangnya pengalaman partikular dari para perempuan ini tidak dielaborasi dan justru dengan segera dihilangkan begitu saja begitu narasi film berjalan.

Penjelasan yang disampaikan dalam voice over perempuan itu sebetulnya menggarisbawahi fakta yang sering menjadi sumber keprihatinan kaum ekofeminis, bahwa perempuan adalah pihak yang dianggap bodoh dan dibodohi dalam penanganan krisis dan konservasi air. Maka, seperti dalam narasi film itu, para perempuan yang ada di desa tersebut disuruh mengungsi, entah kemana, tidak dijelaskan lebih lanjut. Para perempuan di desa itu yang pasti seperti diceritakan oleh voice-over harus pergi dan menjauhkan diri dari desa. Mereka belum boleh pulang [oleh para lelaki di desa itu] dan hanya diberi infomasi bahwa keadaan di desa mereka aman-aman saja. Toh sudah ada banyak laki-laki di desa. Voice over itu menyuarakan kecurigaan bahwa ada yang tidak beres dengan kejadian di desanya itu. Ia juga menggarisbawahi bahwa ia dan para perempuan lainnya adalah pihak yang tidak tahu apa-apa, yang mungkin sedang dibodohi oleh pihak-pihak tertentu yang terlibat dalam krisis kelangkaan air. Hal ini sebetulnya merupakan titik awal yang cukup krusial untuk membicarakan problem kelangkaan air yang terjadi akibat adanya beragam konspirasi yang merugikan masyarakat desa, termasuk kaum perempuan. Akan tetapi, film ini memilih untuk berhenti pada fakta bahwa perempuan dibuat berjarak dan dijauhkan dengan persoalan krisis air. Mereka dipinggirkan atau seolah-olah "diamankan" dari situasi di mana mereka sebetulnya terdampak langsung dan ikut berkontribusi untuk memikirkan solusi atau jalan keluarnya. Mengapa film ini tidak memilih untuk juga menyoroti pengalaman perempuan yang disuruh mengungsi di tengah krisis air itu? Bagaimana para perempuan yang diminta pergi itu memandang persoalan kelangkaan air itu? Pertanyaan-pertanyaan ini menunjukkan indikasi betapa dominannya perspektif laki-laki yang digunakan di dalam film ini.

Film ini bukannya mengelaborasi fakta bahwa perempuan sering dipinggirkan dan bahkan dieksklusikan dalam penanganan krisis air. Sebaliknya, film Seorang Kambing justru ikut mereproduksi praktik eksklusi dengan meniadakan sosok perempuan dalam seluruh mise en scène. Film ini ibarat koran yang memuat pemberitaan tentang kekerasan seksual pada perempuan, dan justru ikut mempraktikkan serta mereproduksi kekerasan itu lewat penggunaan bahasa-bahasa yang cenderung misoginis. Film Seorang Kambing berkomentar tentang peminggiran perempuan dalam konflik air, tetapi sekaligus ikut mempraktikkan peminggiran tersebut melalui penggunaan estetika film yang cenderung maskulin.

Selain karakterisasi yang menonjolkan laki-laki, film ini juga memfungsikan beragam tanda dan ungkapan figuratif serta stylization yang bias laki-laki. Beberapa di antaranya adalah penggunaan motor trail, harimau, aktivitas bela diri dan juga kehadiran militer yaitu tentara. Kehadiran kelompok bela diri dan tentara merupakan dua contoh bagaimana film ini sengaja membangun citra hypermasculinity atau maskulinitas hiper dalam film ini. Merujuk pada kajian Vanda Burstyn (1999), Michael Kimmel dan Amy Aronson (2004: 418) mengungkapkan definisi maskulinitas hiper sebagai "an exaggerated ideal manhood linked mythically and practically to the role of the warrior". Jadi, maskulinitas hiper adalah konstruksi ideal manhoood yang diasosiasikan dengan dominasi, kekerasan dan juga kekuatan fisik. Aktivitas bela diri yang menonjolkan kekuatan dan menampilkan kekerasan jelas merupakan aktivitas yang menonjolkan olah dan kekuatan fisik, yang sering diasosiasikan 
dengan hasrat agresif laki-laki. Sementara, militer sudah dikenal sebagai institusi yang kental dengan kultur maskulinitas hipernya (lihat Brown, 2006; Digby, 2014). Dalam film itu, maskulinitas hiper ditampilkan lewat praktik unjuk kekuatan fisik yang dilakukan baik oleh kelompok beladiri maupun kelompok militer, dalam hal ini tentara, misalnya di menit 14:05-15:05, ketika anggota kelompok beladiri mengeroyok, memukuli dan menendangi dua anggota tentara. Memang film ini tidak berupaya melakukan glorifikasi kekerasan seperti dalam film-film Hollywood semacam Once Upon A Time in the West (Sergio Leone, 1969) atau Dirty Harry (Don Siegel, 1971) seperti yang dikaji oleh Stella Bruzzi (2013). Sebaliknya, beberapa adegan pemukulan dan penendangan dalam film Seorang Kambing sengaja dihitamkan dan disembunyikan secara visual. Akan tetapi, penonton tetap diajak untuk terus mengikuti berlangsungnya adegan itu lewat suara pukulan, tendangan, dan erangan. Artinya kekerasan agresif tidak hilang begitu saja, hanya sebagian adegan disembunyikan secara visual. Adegan kekerasan agresif sebagai simbol maskulinitas hiper juga ditampilkan dari tindakan pemuda desa ketika memukul kepala laki-laki bemotor trail hingga pingsan. Memang kejadian pada saat kepalanya dihantam dengan botol air yang besar tidak mengalami estetikasi, dan ditonjolkan secara vulgar, tetapi kejadian itu diindikasikan lewat adegan setelahnya, yaitu adegan yang menunjukkan ketika sosok lakilaki itu pingsan. Kohesi dari rangkaian adegan itu secara tidak langsung menggarisbawahi citra maskulinitas hiper yang dihadirkan di dalam film itu.

Problem kelangkaan air menjadi sebuah arena di mana kekuatan-kekuatan maskulin saling berkompetisi dan bertarung untuk memenangkan kuasa dan pengaruh. Untuk itu, kekuatan maskulin cenderung berhasrat untuk menghancurkan, tidak hanya menghancurkan kekuatan maskulin yang lain di sekitarnya, tetapi juga yang feminin. Hal ini direpresentasikan melalui adegan yang menarasikan tindakan pembakaran untuk mengasapi gua, yang disinyalir sebagai tempat persembunyian harimau. Alam yang dikonotasikan sebagai feminin pun ikut dirusak dan dibakar untuk menundukkan makhluk lain yang menjadi metafora dari kejantanan dan kebuasan, yaitu harimau.

Pilihan metafora harimau pun cukup menarik untuk dilihat. Film ini mendudukkan harimau yang dicurigai sebagai biang keladi hilangnya kambing-kambing ke dalam posisi yang beririsan dengan tokoh 'Mas Trail' sebagai representasi dari korporasi yang berperan dalam program privatisasi air. Harimau dalam konteks ini menjadi metafora dari keserakahan dan kebuasan industri yang mencaplok dan menggerus hak warga atas air. Harimau adalah metafora untuk menarasikan perilaku-perilaku buruk manusia yang merugikan manusia yang lain. Manusia, dalam hal ini, sering mendudukkan diri sebagai "Übermensch" atau manusia super yang lebih tinggi kedudukannya dibandingkan makhluk yang lain, termasuk binatang (Candraningrum, 2014: 14). Akibatnya untuk menutupi sifat buruknya dan mengangkat derajatnya sebagai manusia super, binatang pun dikorbankan, direndahkan, dituding dengan segala label buruk, dan digunakan untuk memersonifikasikan keburukan manusia. Harimau pun mengalami feminisasi, distigmatisasi dan dipaksa menanggung sifat buas manusia. Pada titik ini, interdependensi dan kesetaraan posisi alam dan manusia dibuat koyak. Ironisnya kekoyakan ini justru dianut dan direproduksi oleh film yang tampaknya dimaksudkan sebagai film yang akan menyampaikan sebuah kesadaran ekologis.

\section{SIMPULAN}

Film Seorang Kambing perlu diapresiasi sebagai sebuaheco-cinema yang mengedepankan kritik ekologi dalam membahas dan berbicara tentang krisis dan kelangkaan air. Meskipun demikian, sebagai sebuah eco-cinema, film tersebut perlu mendalami kompleksitas problem di seputar krisis dan kelangkaan air. Film Seorang Kambing cenderung mengabaikan perspektif ekofeminis dalam membingkai krisis air, sehingga film ini terkesan sangat maskulin dan mereproduksi peminggiran dan bahkan 
eksklusi perempuan dalam wacana krisis dan kelangkaan air bersih. Pilihan-pilihan estetika dalam film tersebut berperan cukup signifikan dalam membangun definisi dan pemahaman tentang maskulinitas. Naratif film Seorang Kambing sangat jelas menggarisbawahi sentralitas laki-laki, baik dari segi karakterisasi maupun fokalisasi. Estetika film yang sangat maskulin ditunjukkan mulai dari penghapusan karakter perempuan dari mise-en-scène, penggunaan simbol dan metafora visual yang bias laki-laki hingga penggunaan style yang menguatkan konstruksi maskulinitas. Kajian atas penggunaan estetika maskulin mampu menguak fakta bahwa film Seorang Kambingyang dimaksudkan sebagai ruang eko-kritik, justru gagal untuk menghadirkan ruang emansipasi bagi perempuan terkait isu lingkungan. Alihalih memberi ruang representasi bagi suara dan pengalaman perempuan dalam isu manajemen dan krisis air, film ini pada akhirnya justru ikut meminggirkan dan mengabaikan pentingnya peran perempuan dalam isu krisis dan kelangkaan air, serta mereproduksi feminisasi alam oleh manusia [baca: laki-laki].

\section{DAFTAR PUSTAKA}

Alex, Rayson K. dan Deborah, S. Susan. 2016. "Introduction: The Ethics of Relationships in Social Documentaries." Dalam Ecodocumentaries: Critical Essays, London: Palgrave Macmillan. Hal. 1-8

Brown, George R. 2006. "Transsexuals in the Military: Flight into Hypermasculinity." Dalam The Transgender Reader. Diedit oleh Susan Styker dan Stephen Whittle, New York dan London: Routledge. Hal. 537-544

Bruzzi, Stella. 2013. Men's Cinema: Masculinity and Mise en Scène in Hollywood, Edinburg: Edinburg University Press.

Candraningrum, Dewi. 2014. “Under Keningar Tree, the Bulls Drink No More: Myth of Mother Merapi". Dalam Body Memories: Goddesses of Nusantara, Rings of Fire and Narratives of Myth, Salatiga: Yayasan Jurnal
Perempuan dan PPSG UKSW. Hal 11-23

Digby, Tom. 2014. Love and War: How Militarism Shapes Sexuality and Romance, New York: Columbia University Press

Eaton, Heather dan Lorentzen, Lois Ann. 2003. "Introduction". Dalam Ecofeminism and Globalization: Exploring Culture, Context and Religion. Oxford, UK: Rowman \& Littlefield. Hal. 1-8

Fulton, Helen. 2005. "Film Narrative and Visual Cohesion". Dalam Narrative and Media. Diedit oleh Helen Fulton, Rosemary Huisman, Julian Murphet dan Anne Dunn, Cambridge, United States: Cambridge University Press. Hal. 108-122

Ingram, David. 2013. "The Aesthetics and Ethics of Eco-Film Criticism". Dalam Ecocinema Theory and Practice. Diedit oleh Stephen Rust, Salma Monani dan Sean Cubitt, London: Routledge. Hal 43-62 Kimmel, Michael dan Aronson, Amy. 2004. Men and Masculinities: A Social, Cultural and Historical Encyclopedia. Vol. 1: A-J, California, Colorado, Oxford: ABC Clio

Kompas.com. 2019. Jawa, Bali, dan Nusa Tenggara Terancam Krisis Air Bersih. Kompas.com. Diakses pada tanggal 26 Maret 2019 (https://properti.kompas.com/ $\mathrm{read} / 2019 / 03 / 26 / 192001621 /$ jawabali-dan-nusa-tenggara-terancamkrisis-air-bersih)

MacDonald, Scott. 2013. "The Ecocinema Experience". Dalam Ecocinema Theory and Practice. Diedit oleh Stephen Rust, Salma Monani dan Sean Cubitt, London: Routledge. Hal. 17-42

Media Indonesia. 2016. Krisis Air Bersih Ancaman Serius. Media Indonesia. Diakses pada tanggal 15 Agustus 2017. (http://mediaindonesia.com/ 
news/read/34184/krisis-air-bersihancaman-serius/2016-03-15)

Mies, Maria dan Shiva, Vandana. 2014. "Introduction: Why We Wrote This Book Together". Dalam Ecofeminism, London: Zed Books. Hal. 1-21

Neale, Steve. 1983. "Masculinity as Spectacle: Reflections on Men and Mainstream Cinema". Screen 24(6): 2-16

Onn, Lee Poh dan Yia, Ng Boon. 2013. "Introduction". Dalam Water Issues in Southeast Asia: Present Trends and Future Direction. Diedit oleh Lee Poh ON, Singapore: ISEAS. Hal. 1-26

Prakarti. 2016. Prakarti: Cerita Tentang Alam dan Kita. Prakarti. Diakses pada tanggal 15 Agustus 2017 (http:// prakarti.id/tentang.html)

Rabiger, Michael. 2008. Directing Film Techniques and Aesthetics. Edisi Keempat. Oxford: Elsevier dan Focal Press

Republika.co.id.2018. PengambilanAirTanah Secara Ilegal, Ini Komentar PAM Jaya. Republika.co.id. Diakses pada tanggal 27 Juli 2019. (https://www. republika.co.id/berita/nasional/ jabodetabek-nasional/18/03/15/ p5mvwj409-pengambilan-air-tanahsecara-ilegal-ini-komentar-pamjaya)

Ruether, Rosemary Radford. 2001. “Deep Ecology, Ecofeminism and the Bible". Dalam Deep Ecology of World
Religions: New Essays on Sacred Ground. Diedit oleh David Landis Barnhill dan Roger S. Gottlieb, Albany, New York: State University of New York Press. Hal. 229-242

Rust, Stephen dan Monani, Salma. 2013. "Introduction: Cuts to DissolvesDefining and Situating Ecocinema Studies". Dalam Ecocinema Theory and Practice. Diedit oleh Stephen Rust, Salma Monani dan Sean Cubitt, London: Routledge. Hal. 1-14

Shiva, Vandana, 1988. Staying Alive: Women, Ecology and Survival in India, New Delhi: kali for women

2001. Water Wars: Privatization, Pollution and Profit, California: North Atlantic Book

Sim, Low Kwai dan Balamurugan, G. 1991. "Urbanization and Urban Water Poblems in Southeast Asia: A Case of Unsustainable Development." Journal of Environmental Management, 32(3):195-209

Wallace, Tina dan Coles, Anne. 2005. "Gender, Water and Development: An Introduction". Dalam Gender, Water and Development, Oxford and New York: Berg Publisher. Hal 1-20.

Willoquet-Maricondi, Paula. 2010. Framing the World: Explorations in Ecocriticism and Film, Virginia, United States: University of Virginia Press. 